\title{
Construction of MoO3/MoSe2 nanocomposite based gas sensor for low detection limit trimethylamine sensing at room temperature
}

\section{Lanjuan Zhou}

China University of Petroleum Huadong - Qingdao Campus

\section{Qian Mi}

China University of Petroleum Huadong - Qingdao Campus

\section{Yingbo Jin}

China University of Petroleum Huadong - Qingdao Campus

Tingting Li ( $\sim$ litingting0406@163.com )

China University of Petroleum Huadong - Qingdao Campus https://orcid.org/0000-0001-5272-4551

\section{Dongzhi Zhang}

China University of Petroleum Huadong - Qingdao Campus

\section{Research Article}

Keywords: Molybdenum trioxide, Hydrothermal method, TMA sensor, MoO3/MoSe2 heterostructure

Posted Date: March 22nd, 2021

DOl: https://doi.org/10.21203/rs.3.rs-336116/v1

License: (c) (i) This work is licensed under a Creative Commons Attribution 4.0 International License. Read Full License 


\section{Abstract}

In this paper, $\mathrm{MoO}_{3} / \mathrm{MoSe}_{2} \mathrm{n}-\mathrm{n}$ heterostructure was constructed for fabricating trimethylamine (TMA) gas sensor by an improved hydrothermal and spin-coating method. The surface morphology and microstructure of the prepared materials were analyzed by XRD, XPS, SEM and TEM characterization methods. The microstructural characterization results demonstrated that the $\mathrm{MoO}_{3} / \mathrm{MoSe}_{2}$ heterostructure had been successfully synthesized, in which the $\mathrm{MoSe}_{2}$ had a flower-shaped structure, and $\mathrm{MoO}_{3}$ had a rod-shaped structure. At the same time, the $\mathrm{MoSe}_{2}$ surface exhibited periodic honeycomb structure. The gas-sensitivity experimental results showed that the proposed $\mathrm{MoO}_{3} / \mathrm{MoSe}_{2}$ sensor had excellent TMA sensing performance at room temperature, including high response capability, low detection limit (20 ppb), short response/recovery time (12 s/19 s), long-term stability, good repeatability and outstanding selectivity. The heterostructure of $\mathrm{MoO}_{3} / \mathrm{MoSe}_{2}$ had made outstanding contributions to the enhanced TMA gas sensing performance at room temperature.

\section{Introduction}

Trimethylamine (TMA) is a kind of colorless gas, whose vapor can form explosive mixture in air, and it will burn and explode violently when exposed to open flames or high heat, resulting in toxic smoke after thermal decomposition, which poses a great threat to human safety. Human exposure to TMA can cause severe irritation to eyes, nose and skin, and even affect the nervous system [1]. The American Conference of Governmental Industrial Hygienists recommend that the TMA concentrations of people exposed to for long and short periods should not exceed 5 and $15 \mathrm{ppm}$, respectively [2]. Interestingly, fresh fish meat contains umami trimethylamine oxide. After the fish dies, trimethylamine oxide is easily reduced to trimethylamine, and trimethylamine makes the fish smell stench [3 - 4]. In life, TMA can be used as a biomarker to assess the freshness of fish and other seafood. Seafood with a TMA concentration exceeding $10 \mathrm{ppm}$ is evaluated as rotten [5 - 6]. In addition, patients with trimethylaminuria have congenital inability to metabolize trimethylamine, who will release it through breathing, urine and sweat, thus resulting patients with fishy smell. Therefore, TMA is expected to play a role in disease diagnosis. Overall, the development of TMA sensors is essential for air quality detection and human health monitoring.

As a typical n-type semiconductor, molybdenum trioxide $\left(\mathrm{MoO}_{3}\right)$ is an important candidate material in gas sensing [7 - 10]. Especially when detecting TMA, because the surface of $\mathrm{MoO}_{3}$ contains a large number of lewis acid sites, it can react strongly with alkaline TMA [11]. For example, Yang et al. prepared ultra-long flexible $\mathrm{MoO}_{3}$ nanoribbons. $\mathrm{MoO}_{3}$ nanoribbons gas sensor had good selectivity for trimethylamine, and the response to $50 \mathrm{ppm}$ TMA was $582\left(240^{\circ} \mathrm{C}\right)$ [12]. Shen et al. synthesized twodimensional (2D) ultra-thin $\mathrm{a}-\mathrm{MoO}_{3}$ nanosheets with oxygen vacancies, with porous surface of $2-10 \mathrm{~nm}$ pore size. At a relatively low operating temperature $\left(133^{\circ} \mathrm{C}\right)$, the response of $\mathrm{a}-\mathrm{MoO}_{3}$ nanosheets gas sensor to 50 ppm TMA was 198 and the detection limit was 20 ppb [6]. As we all know, sensor performance is largely due to the morphology of the metal oxide. Compared with other nanostructures, 
one-dimensional (1D) nanostructure has larger specific surface area. Therefore, super-dispersed ultralong $\mathrm{MoO}_{3}$ nanorods were synthesized by an improved hydrothermal method. In addition, TMA sensors based on $\mathrm{MoO}_{3}$ usually require higher operating temperature, resulting in high power consumption and potential safety hazards, so it is necessary to dope other semiconductors to improve the sensing performance.

2D layered material molybdenum selenide $\left(\mathrm{MoSe}_{2}\right)$ has attracted great attention because of its wellknown semiconductor properties. $\mathrm{MoSe}_{2}$ is widely used especially as catalyst [13 - 16] and electrode material [17 - 19]. In addition, $\mathrm{MoSe}_{2}$ also shows superior performance in the field of gas sensing. For example, Zhang et al. used $\mathrm{MoSe}_{2}$ nanosheets by liquid phase exfoliation as starting materials, and prepared $\mathrm{MoSe}_{2}$ nanosheets with controllable lateral dimension by controlling the centrifugal condition, which provided basis for the study of relationship between sensing characteristics and material sizes. The results showed that $\mathrm{MoSe}_{2}$ nanosheets have more competitive advantages than traditional graphene-based sensors [20]. Also using the convenient method of liquid phase exfoliation, the $\mathrm{MoSe}_{2}$ nanosheets exfoliated by Chen et al. had significantly enhanced $\mathrm{NO}_{2}$ detection performance. Sensor response to $10 \mathrm{ppm} \mathrm{NO}$ was $1500 \%, 18$ times the original $\mathrm{MoSe}_{2}$, and the detection limit was as low as $50 \mathrm{ppb}$, while showed excellent selectivity and stability, making $\mathrm{MoSe}_{2}$ nanosheets a good choice for $\mathrm{NO}_{2}$ sensors at room temperature (RT) [21]. Zhang et al. synthesized Pd-MoSe $e_{2}$ thin film sensor by modifying $\mathrm{MoSe}_{2}$ nanoflowers with Pd, confirming that Pd-decorated $\mathrm{MoSe}_{2}$ nanoflowers were good choice for RT $\mathrm{NH}_{3}$ detection [22].

In order to solve the problem of high power consumption of $\mathrm{MoO}_{3}$ and improve the gas-sensing performances, room temperature TMA sensor based on heterostructure of $\mathrm{MoSe}_{2}$ nanoflower-modifed $\mathrm{MoO}_{3}$ was prepared by a simple hydrothermal method. The microstructure and surface morphology of the samples were investigated by a series of characterization techniques such as XRD, XPS, SEM and TEM. For the sake of further investigating the effect of the synergy of the two materials on sensing properties, the relevant gas sensing experiments of single $\mathrm{MoSe}_{2}$ and $\mathrm{MoO}_{3} / \mathrm{MoSe}_{2}$ were also conducted. The results showed that compared with single sensing material, the $\mathrm{MoO}_{3} / \mathrm{MoSe}_{2}$ composite-based sensor exhibited more excellent sensing properties to TMA in terms of selectivity, sensitivity, response/recovery time and minimum detection limit. At the same time, the sensing mechanism was also explained in detail based on the theory of oxygen adsorption and desorption on the semiconductor surface and $n-n$ heterostructure theory.

\section{Experiment}

\subsection{Materials}

Molybdenum powder, selenium powder, sodium borohydride $\left(\mathrm{NaBH}_{4}\right)$, sodium molybdate $\left(\mathrm{Na}_{2} \mathrm{MoO}_{4} \cdot 2 \mathrm{H}_{2} \mathrm{O}\right), \mathrm{H}_{2} \mathrm{O}_{2}$ and ethanol were purchased by Sinopharm Chemical Reagent (Shanghai, China). 


\subsection{Materials synthesis}

\subsubsection{Synthesis of $\mathrm{MoO}_{3}$ nanorods}

The ultra-long $\mathrm{MoO}_{3}$ nanorods were synthesized by an improved hydrothermal method. Firstly, $2 \mathrm{~g}$ of molybdenum powder was added into $10 \mathrm{~mL}$ deionized water (DI) with thorough mixing. Then, $20 \mathrm{~mL}$ of $\mathrm{H}_{2} \mathrm{O}_{2}$ was slowly added to the above solution until it became pale yellow, and stirring was continued for $30 \mathrm{~min}$ to make reaction thorough. After that, the resulting solution was transferred to a $50 \mathrm{~mL}$ autoclave, then heated to $220^{\circ} \mathrm{C}$ and maintained for $48 \mathrm{~h}$ [23]. Finally, after the reactor was cooled to RT, the precipitate was filtered and washed with DI and ethanol for several times to remove impurities, thereby obtaining pure $\mathrm{MoO}_{3}$ suspension.

\subsubsection{Synthesis of $\mathrm{MoSe}_{2}$ nanoflowers}

The hydrothermal method was also used to synthesize $\mathrm{MoSe}_{2}$ nanoflowers. Firstly, $0.493 \mathrm{~g}$ of selenium powder was dissolved in $10 \mathrm{~mL}$ hydrazine hydrate solution. Then, the dissolved Se powder solution, $0.1 \mathrm{~g}$ of $\mathrm{NaBH}_{4}, 0.6 \mathrm{~g}$ of $\mathrm{Na}_{2} \mathrm{MoO}_{4} \cdot 2 \mathrm{H}_{2} \mathrm{O}$ and $25 \mathrm{~mL}$ of ethanol were added into $25 \mathrm{~mL}$ DI, and continued stirring for $1 \mathrm{~h}$. Next, the resulting mixture was transferred to a $100 \mathrm{~mL}$ autoclave and heated at $200^{\circ} \mathrm{C}$ for $48 \mathrm{~h}$. Finally, DI was used to wash and filter the obtained black fluffy material to remove excess impurity ions, thereby obtaining pure $\mathrm{MoSe}_{2}$ suspension.

\subsubsection{Synthesis of $\mathrm{MoO}_{3} / \mathrm{MoSe}_{2}$ nanocomposite}

$\mathrm{MoO}_{3} / \mathrm{MoSe}_{2}$ was prepared by a two-step hydrothermal method. During the synthesis of $\mathrm{MoSe}_{2}$, before the mixture was transferred to autoclave, a quantitative $\mathrm{MoO}_{3}$ suspension synthesized by a hydrothermal method was added. The above mixed solution was sonicated for $2 \mathrm{~h}$, then transferred to a $100 \mathrm{~mL}$ autoclave. $\mathrm{MoO}_{3} / \mathrm{MoSe}_{2}$ composite material was finally obtained. The synthesis process is shown in Fig. 1.

\subsection{Characterization and measurement}

The $\mathrm{MoO}_{3} / \mathrm{MoSe}_{2}$ suspension was spin coat on the surface of the interdigitated electrode by a spin coating process, and then the aging treatment was performed on the obtained sensor device at room temperature. For better studying the performance characteristics of thin film devices and analyzing the materials from microscopic perspective, $X$-ray diffractometer (XRD), scanning electron microscope (SEM), transmission electron microscope (TEM), X-ray photoelectron spectroscope (XPS) and other precision equipment were used to characterize the sensor materials. The sensor performances were studied by exposure to different concentrations of target gases at RT. The sensor resistance will change due to the change of the target gas concentration. The data were recorded by the Agilent data acquisition instrument (Agilent 34970A) and uploaded to PC via the RS-232 bus, which could then be stored, 
analyzed and processed. The sensor performance is represented by the response calculated by $S=$ $100 \% \times\left(R_{a}-R_{g}\right) / R_{a}$. Here, $R_{a}$ and $R_{g}$ represent sensor resistance values in air and target gas, respectively.

\section{Results And Discussion}

\subsection{Materials characterization}

XRD characterization diagrams of $\mathrm{MoSe}_{2}, \mathrm{MoO}_{3}$ and $\mathrm{MoO}_{3} / \mathrm{MoSe}_{2}$ heterostructure are shown in Fig. 2, with a test angle range from $10^{\circ}$ to $60^{\circ}$. From the XRD pattern of $\mathrm{MoO}_{3}$, three high-intensity diffraction peaks can be observed, which indicates that $\mathrm{MoO}_{3}$ is a highly ordered orthorhombic crystal [23]. The angles of all diffraction peaks of $\mathrm{MoO}_{3}$ are $13.2^{\circ}, 23.8^{\circ}, 26.1^{\circ}, 27.4^{\circ}, 38.6^{\circ}, 42.3^{\circ}, 46.6^{\circ}$ and $53.3^{\circ}$, respectively, which correspond to the (020), (110), (040), (021), (060), (141), (200) and (211) crystal planes of $\mathrm{MoO}_{3}$ [24]. The XRD confirms that the synthesized $\mathrm{MoO}_{3}$ contains no other impurities. In the XRD pattern of $\mathrm{MoSe}_{2}$, the peaks at $14.1^{\circ}, 33.2^{\circ}, 37.1^{\circ}$ and $55.9^{\circ}$ correspond to the (002), (100), (103) and (110) crystal planes of $\mathrm{MoSe}_{2}$ [25]. The black line in the figure contains the characteristic diffraction peaks of $\mathrm{MoSe}_{2}$ and $\mathrm{MoO}_{3}$, which shows that the $\mathrm{MoO}_{3} / \mathrm{MoSe}_{2}$ heterostructure has been successfully synthesized.

SEM characterization was performed to further verify the successful preparation and visually observe the morphology of the prepared materials. Figure 3 shows the SEM characterization results of $\mathrm{MoSe}_{2}, \mathrm{MoO}_{3}$ and $\mathrm{MoO}_{3} / \mathrm{MoSe}_{2}$ heterostructure. It can be found from Fig. 3 (a) that $\mathrm{MoSe}_{2}$ is flower-shaped structure as a whole, and it has a porous structure. The surface of $\mathrm{MoO}_{3}$ in Fig. 3 (b) has a high degree of crystallinity, and its overall shape is a long rod. Figures 3 (c-d) are SEM characterizations of the $\mathrm{MoO}_{3} / \mathrm{MoSe}_{2}$ heterostructure. We can clearly observe the tightly coupled morphology of the two, indicating the successful synthesis of the two materials.

TEM characterization of the prepared materials is shown in Fig. 4. Figure 4 (a) is the micro-morphology of the $\mathrm{MoO}_{3} / \mathrm{MoSe}_{2}$ heterostructure. It can be observed that the aggregated flower-like shaded part is $\mathrm{MoSe}_{2}$, and the rod-shaped object on the upper right is $\mathrm{MoO}_{3}$, which shows that the two substances have been combined together closely. Figure 4 (b) is the TEM characterization diagram of $\mathrm{MoO}_{3}$. The rodshaped $\mathrm{MoO}_{3}$ morphology can be clearly seen, and its width is about $400 \mathrm{~nm}$. The inset is the electron diffraction pattern (SAED) of partial region of single $\mathrm{MoO}_{3}$. Figure 4 (c) is TEM characterization diagram of $\mathrm{MoSe}_{2}$. It can be found that $\mathrm{MoSe}_{2}$ is flower-like shape composed of thin layers. The inset is the SAED of partial area of single $\mathrm{MoSe}_{2}$. Figures 4 (d-e) are HRTEM characterization diagrams of $\mathrm{MoO}_{3}$ and $\mathrm{MoSe}_{2}$, respectively. The lattice fringe spacings of 0.33 and $0.41 \mathrm{~nm}$ correspond to the (021) and (200) crystal planes of $\mathrm{MoO}_{3}$, respectively. The spacings of 0.28 and $0.67 \mathrm{~nm}$ correspond to the (100) and (002) crystal planes of $\mathrm{MoSe}_{2}$, respectively [26 - 27]. In order to clearly observe the atomic distribution on the surface of $\mathrm{MoSe}_{2}$, some designated areas in Fig. 4 (e) are enlarged, as shown in Fig. 4 (f). The MoSe 2 
surface exhibits periodic honeycomb structure, which shows that the prepared $\mathrm{MoSe}_{2}$ has a graphene-like planar structure [25].

Figure 5 is XPS characterization result of $\mathrm{MoO}_{3} / \mathrm{MoSe}_{2}$ heterostructure. The XPS full spectrum in Fig. 5 (a) indicates that the sample contains elements of Mo, Se, $\mathrm{O}$, and a small amount of $\mathrm{C}$. The source of $\mathrm{C}$ may be some organic contaminants remaining on the surface of the sample. Figure 5 (b) shows the spectrum of Mo element. The characteristic peaks appearing at 232.17 and $229.02 \mathrm{eV}$ correspond to the Mo $3 d_{3 / 2}$ and Mo $3 d_{5 / 2}$ orbitals of molybdenum tetravalent, respectively, and it is because that $\mathrm{MoSe}_{2}$ contains Mo-Se bonds [28]. While in $\mathrm{MoO}_{3}$, the characteristic peaks at 236.18 and $233.05 \mathrm{eV}$ correspond to $M o 3 d_{3 / 2}$ and $M o 3 d_{5 / 2}$ orbitals of hexavalent molybdenum, respectively [29]. The characteristic peaks at 55.35 and $54.45 \mathrm{eV}$ in Fig. 5 (c) respectively correspond to the Se $3 d_{3 / 2}$ and $S e 3 p_{5 / 2}$ orbits of Se${ }^{2-}$ [28]. Figure 5 (d) is the spectrum of 0 element, in which the low binding energy of $530.75 \mathrm{eV}$ is derived from the $\mathrm{Mo}-\mathrm{O}$ bond in $\mathrm{MoO}_{3}$, and the high binding energy of $531.25 \mathrm{eV}$ corresponds to the oxygen adsorbed on the sample surface [29]. The XPS characterization results also prove the successful synthesis of the composite materials.

\subsection{Sensing performance}

The experiment results of the sensors on exposure to different concentrations of trimethylamine at RT are shown in Fig. 6. Figure 6 (a) is the dynamic response diagram of $\mathrm{MoSe}_{2}$ sensor and $\mathrm{MoO}_{3} / \mathrm{MoSe}_{2}$ heterostructure sensor switching back and forth in air and TMA from 20 to 1000 ppb. Both sensors have good response and recovery characteristics, but $\mathrm{MoO}_{3} / \mathrm{MoSe}_{2}$ nanocomposite sensor shows higher response values at the same concentration of TMA gas. Moreover, $\mathrm{MoO}_{3} / \mathrm{MoSe}_{2}$ sensor can detect TMA as low as $20 \mathrm{ppb}$ with high sensitivity, whose response is as high as $19 \%$. Figure 6 (b) shows the fitting curves of the response values and gas concentrations of the two. Among them, the fitting curve of $\mathrm{MoO}_{3} / \mathrm{MoSe}_{2}$ heterostructure sensor is $Y=6.1861 X^{0.3544}$, and the regression coefficient $R^{2}$ is 0.9912 . The response fitting curve of $\mathrm{MoSe}_{2}$ sensor is $Y=1.6909 \mathrm{X}^{0.4396}$, and $\mathrm{R}^{2}$ is 0.9856 . Figure 6 (c) is the dynamic resistance change of $\mathrm{MoO}_{3} / \mathrm{MoSe}_{2}$ nanocomposite sensor. When the sensor is switched from air to trimethylamine environment, its resistance values emerge a downward trend, which shows that the sensor as a whole is n-type. Figure 6 (d) shows the response/recovery characteristics of two sensors to $1000 \mathrm{ppb}$ TMA. It is not difficult to find that $\mathrm{MoO}_{3} / \mathrm{MoSe}_{2}$ nanocomposite sensor not only has a higher response value, but also has a faster response speed, which further illustrates that the $\mathrm{MoO}_{3} / \mathrm{MoSe}_{2}$ heterostructure helps to improve the gas sensing performance.

Figure 7 (a) shows the long-term stability of $\mathrm{MoO}_{3} / \mathrm{MoSe}_{2}$ nanocomposite sensor. Every two days, the sensor was tested on exposure to different concentrations (50,250 and $500 \mathrm{ppb}$ ) of TMA, and the results show that the sensor is stable enough. When studying sensor performances, it is necessary to explore the effect of humidity on sensor response. Figure 7 (b) is the fitting curve of the response of $\mathrm{MoO}_{3} / \mathrm{MoSe}_{2}$ heterostructure sensor to $250 \mathrm{ppb}$ TMA under different humidity conditions. The fitting equation is $\mathrm{Y}=$ 
$55.672-0.215 X$, where the horizontal axis $X$ is relative humidity, vertical axis $Y$ is the response value of the sensor, and the regression coefficient $\mathrm{R}^{2}$ is 0.939 , which shows that the influence of humidity on the sensor is regular. The repeatability test was also performed on the sensor, as shown in Fig. 7 (c). $\mathrm{MoO}_{3} / \mathrm{MoSe}_{2}$ sensor was tested in air and fixed concentration of TMA gas for five cycles, respectively. The experimental results show that the sensor has good recoverability. The selectivity of the sensor to target gas is very important. As shown in Fig. 7 (d), compared with other interfering gases, $\mathrm{MoO}_{3} / \mathrm{MoSe}_{2}$ nanocomposite sensor and $\mathrm{MoSe}_{2}$ sensor have higher response values to TMA, indicating that test sensors have good selectivity to TMA.

Table 1 lists the comparison of TMA response characteristics among $\mathrm{MoO}_{3} / \mathrm{MoSe}_{2}$ based sensor in this work and previously reported sensors. It can be found that compared with the previous reported TMA sensors, the $\mathrm{MoO}_{3} / \mathrm{MoSe}_{2}$ sensor not only has a very low detection limit and higher response, but also has a lower working temperature, which can be used in room temperature. Therefore, the sensor proposed in this paper can be an excellent candidate for TMA detection.

Table 1

Comparison of TMA sensing performance of as-fabricated $\mathrm{MoO}_{3} / \mathrm{MoSe}_{2}$ based sensor against previous reported results.

\begin{tabular}{|lllll|}
\hline Materials & Working Temp. & Response & LOD & Ref. \\
\hline $\mathrm{Pd}-\mathrm{ZnO}$ & $300^{\circ} \mathrm{C}$ & $2.9(1 \mathrm{ppm})$ & $1 \mathrm{ppm}$ & {$[1]$} \\
$\mathrm{a}-\mathrm{MoO}_{3}$ & $133^{\circ} \mathrm{C}$ & $1.25(20 \mathrm{ppb})$ & $20 \mathrm{ppb}$ & {$[12]$} \\
$\mathrm{V}_{2} \mathrm{O}_{5}$ & $240^{\circ} \mathrm{C}$ & $2.8(100 \mathrm{ppm})$ & $10 \mathrm{ppm}$ & {$[30]$} \\
$\mathrm{MoO}_{3} / \mathrm{Bi}_{2} \mathrm{Mo}_{3} \mathrm{O}_{12}$ & $170^{\circ} \mathrm{C}$ & $7.2(10 \mathrm{ppm})$ & $100 \mathrm{ppb}$ & {$[32]$} \\
$\mathrm{V}_{2} \mathrm{O}_{3}-\mathrm{Cu}_{2} \mathrm{O}$ & $\mathrm{RT}$ & $1.08(3 \mathrm{ppm})$ & $3 \mathrm{ppm}$ & {$[33]$} \\
$\mathrm{Co}_{3} \mathrm{O}_{4} / \mathrm{SnO}_{2}$ & $175^{\circ} \mathrm{C}$ & $9.3(5 \mathrm{ppm})$ & $1 \mathrm{ppm}$ & {$[34]$} \\
$3 \mathrm{D} \mathrm{rGO} / \mathrm{In}_{2} \mathrm{O}_{3}$ & $\mathrm{RT}$ & $9.3 \%(100 \mathrm{ppm})$ & $100 \mathrm{ppm}$ & {$[35]$} \\
$\mathrm{CdO}^{\mathrm{Al}}$ & $\mathrm{RT}$ & $32.12 \%(300 \mathrm{ppm})$ & $50 \mathrm{ppm}$ & {$[36]$} \\
$\mathrm{MoO}_{3} / \mathrm{MoSe}_{2}$ & $\mathrm{RT}$ & $19 \%(20 \mathrm{ppb})$ & $20 \mathrm{ppb}$ & This work \\
\hline
\end{tabular}

\subsection{Gas sensing mechanism}

The schematic diagram of the TMA sensing mechanism of $\mathrm{MoO}_{3} / \mathrm{MoSe}_{2}$ sensor is shown in Fig. 8. As a typical n-type semiconductor, the carriers of $\mathrm{MoO}_{3}$ are electrons. It is known from the above gassensitivity test results that the $\mathrm{MoSe}_{2}$ based sensor also exhibits n-type semiconductor characteristics to TMA. In gas sensing process, the $\mathrm{MoO}_{3} / \mathrm{MoSe}_{2}$ heterostructure does not participate in the reaction, it is the oxygen ions adsorbed on the surface that do. In other words, the gas sensing mechanism benefits 
from the adsorption and desorption of oxygen on the sensor surface. Possible reactions are as follows $[31,36]$ :

$\mathrm{O}_{2}$ (gas) $\rightarrow \mathrm{O}_{2}$ (ads) (1)

$\mathrm{O}_{2}$ (ads) $+\mathrm{e}^{-} \rightarrow \mathrm{O}_{2}^{-}$(ads) (2)

$4\left(\mathrm{CH}_{3}\right)_{3} \mathrm{~N}+21 \mathrm{O}_{2}^{-}$(ads) $\rightarrow 2 \mathrm{~N}_{2}+12 \mathrm{CO}_{2}+18 \mathrm{H}_{2} \mathrm{O}+21 \mathrm{e}^{-}$

It can be seen that when the sensor device is transferred from air to TMA environment, a large amount of electrons will be released, so the sensor exhibits lower resistance value. There may be two reasons for the enhanced gas sensing performance of $\mathrm{MoO}_{3} / \mathrm{MoSe}_{2}$ heterostructure sensor. Firstly, $\mathrm{MoO}_{3} / \mathrm{MoSe}_{2}$ composite structure has a large specific surface area [37 - 38], which is conducive to the diffusion of TMA molecules and makes TMA react with adsorbed oxygen thoroughly, thereby enhancing the gas sensing response. Secondly, the heterostructure formed between $\mathrm{MoO}_{3}$ and $\mathrm{MoSe}_{2}$ has synergistic effect. The formation of the heterostructure has an effect on the conductivity of the sensor. After $\mathrm{MoO}_{3}$ is modified with $\mathrm{MoSe}_{2}$ to form the heterostructure, the resistance value of the sensor in air decreases, meaning that the conductivity of the device is improved, which is conducive to the rapid conduction of carriers. The energy band diagram at the interface between $\mathrm{MoO}_{3}$ and $\mathrm{MoSe}_{2}$ and the formation process of the heterostructure are studied, as shown in Fig. 9 . Figure 9 (a) is the energy band diagram before the two substances are combined, in which the band gap of $\mathrm{MoO}_{3}$ and $\mathrm{MoSe}_{2}$ are 3.2 and $1.3 \mathrm{eV}$, the work function is 6.9 and $4.6 \mathrm{eV}$, and the electron affinity is 6.7 and $3.9 \mathrm{eV}$, respectively [39-40]. Figure 9 (b) shows the formation process of the $n-n$ heterostructure in air. At this time, the electron transfer between the two causes the energy band to bend. The change process of the heterostructure in TMA is shown in Fig. 9 (c). The width of the depletion layer is narrowed due to the reaction between TMA and the adsorbed oxygen, so that the sensor shows higher response value and faster response speed.

\section{Conclusions}

In summary, TMA sensor based on $\mathrm{MoO}_{3} / \mathrm{MoSe}_{2} \mathrm{n}$-n heterostructure was proposed in this paper. The microstructures of $\mathrm{MoO}_{3} / \mathrm{MoSe}_{2}$ nanocomposite were characterized by various characterization methods, and the gas sensing properties of $\mathrm{MoSe}_{2}$ and $\mathrm{MoO}_{3} / \mathrm{MoSe}_{2}$ nanocomposite sensors were also tested. The $\mathrm{MoO}_{3} / \mathrm{MoSe}_{2}$ nanocomposite was composed of $\mathrm{MoSe}_{2}$ and $\mathrm{MoO}_{3}$, in which $\mathrm{MoSe}_{2}$ possessed a porous flower-shaped structure, and $\mathrm{MoO}_{3}$ had a long rod structure. The experimental results showed that compared with the single sensing material, the $\mathrm{MoO}_{3} / \mathrm{MoSe}_{2}$ sensor had more excellent sensing performance, which could detect low concentration of TMA gas at RT. The enhanced sensing performance was mainly due to the unique morphology and heterostructure of $\mathrm{MoO}_{3} / \mathrm{MoSe}_{2}$. This work confirmed that the $\mathrm{MoO}_{3} / \mathrm{MoSe}_{2}$ composite sensor was a good choice for TMA detection.

\section{Declarations}




\section{Acknowledgements}

This work was supported by the Independent Innovation Scientific Research Project of China University of

Petroleum (East China) (20CX06065A) and China Postdoctoral Science Foundation (2020M682263).

\section{Notes}

The authors declare no competing financial interest.

\section{References}

1. D. Meng, D. Liu, S. Wang, Y. Shen, X. San, J. Si, F. Meng, In-situ growth of ordered Pd-doped ZnO nanorod arrays on ceramic tube with enhanced trimethylamine sensing performance. Appl. Surf. Sci. 463, 348-356 (2019)

2. S. Park, B. Kim, Y. Jo, Z. Dai, J. Lee, Chemiresistive trimethylamine sensor using monolayer $\mathrm{SnO}_{2}$ inverse opals decorated with $\mathrm{Cr}_{2} \mathrm{O}_{3}$ nanoclusters. Sens. Actuators, B 309, 127805 (2020)

3. Y. Cho, X. Liang, Y. Kang, J. Lee, Ultrasensitive detection of trimethylamine using Rh-doped $\mathrm{SnO}_{2}$ hollow spheres prepared by ultrasonic spray pyrolysis. Sens. Actuators, B 207, 330-337 (2015)

4. L. Balino-Zuazo, A. Barranco, A novel liquid chromatography-mass spectrometric method for the simultaneous determination of trimethylamine, dimethylamine and methylamine in fishery products. Food Chem. 196, 1207-1214 (2016)

5. X. Chu, J. Wang, Q. Gao, Y. Wang, S. Liang, L. Bai, Y. Dong, M. Epifani, High selectivity trimethylamine sensors based on graphene- $\mathrm{NiGa}_{2} \mathrm{O}_{4}$ nanocomposites prepared by hydrothermal method. Physica $\mathrm{E}$ $118,113788(2020)$

6. S. Shen, X. Zhang, X. Cheng, Y. Xu, S. Gao, H. Zhao, X. Zhou, L. Huo, Oxygen-vacancy-enriched porous $\mathrm{aMoO}_{3}$ nanosheets for trimethylamine sensing. ACS Appl. Nano Mater. 2, 8016-8026 (2019)

7. F. Ji, X. Ren, X. Zheng, Y. Liu, L. Pang, J. Jiang, S. Liu, 2D-MoO 3 nanosheets for superior gas sensors. NANOSCALE 8, 8696 (2016)

8. L. Zhang, Z. Liu, L. Jin, B. Zhang, H. Zhang, M. Zhu, W. Yang, Self-assembly gridding-MoO ${ }_{3}$ nanobelts for highly toxic $\mathrm{H}_{2} \mathrm{~S}$ gas sensors. Sens. Actuators, B 237, 350-357 (2016)

9. J. Shen, S. Guo, C. Chen, L. Sun, S. Wen, Y. Chen, S. Ruan, Synthesis of Ni-doped-MoO 3 nanolamella and their improved gas sensing properties. Sens. Actuators, B 252, 757-763 (2017)

10. S. Wang, J. Xie, J. Hu, H. Qin, Y. Cao, Fe-doped a-MoO 3 nanoarrays: Facile solid-state synthesis and excellent xylene-sensing performance. Appl. Surf. Sci. 512, 145722 (2020)

11. H. Li, L. Huang, X. Wang, C. Lee, J. Yoon, J. Zhou, X. Guo, J. Lee, Molybdenum trioxide nanopaper as a dual gas sensor for detecting trimethylamine and hydrogen sulfide. RSC Adv. 7, 3680-3685 (2017)

12. S. Yang, Y. Liu, W. Chen, W. Jin, J. Zhou, H. Zhang, G. Zakharova, High sensitivity and good selectivity of ultralong $\mathrm{MoO}_{3}$ nanobelts for trimethylamine gas. Sens. Actuators, B 226, 478-485 (2016) 
13. S. Mao, Z. Wen, S. Ci, X. Guo, K. Ostrikov, J. Chen, Perpendicularly oriented $\mathrm{MoSe}_{2} /$ graphene nanosheets as advanced electrocatalysts for hydrogen evolution. SMALL 11, 414-419 (2015)

14. S. Deng, Y. Zhong, Y. Zeng, Y. Wang, Z. Yao, F. Yang, S. Lin, X. Wang, X. Lu, X. Xia, J. Tu, Directional construction of vertical nitrogen-doped $1 \mathrm{~T}-2 \mathrm{H} \mathrm{MoSe}_{2} /$ graphene shell/core nanoflake arrays for efficient hydrogen evolution reaction. Adv. Mater. 29, 1700748 (2017)

15. S. Deng, F. Yang, Q. Zhang, Y. Zhong, Y. Zeng, S. Lin, X. Wang, X. Lu, C. Wang, L. Gu, X. Xia, J. Tu, Phase modulation of (1T-2H)-MoSe ${ }_{2} / \mathrm{TiC}-\mathrm{C}$ shell/core arrays via nitrogen doping for highly efficient hydrogen evolution reaction. Adv. Mater. 30, 1802223 (2018)

16. Y. Wu, M. Xu, X. Chen, S. Yang, H. Wu, J. Pan, X. Xiong, CTAB-assisted synthesis of novel ultrathin $\mathrm{MoSe}_{2}$ nanosheets perpendicular to graphene for the adsorption and photodegradation of organic dyes under visible light. NANOSCALE 8, 440-450 (2016)

17. X. Yang, Z. Zhang, Y. Fu, Q. Li, Porous hollow carbon spheres decorated with molybdenum diselenide nanosheets as anodes for highly reversible lithium and sodium storage. NANOSCALE 7, 1019810203 (2015)

18. J. Ge, L. Fan, J. Wang, Q. Zhang, Z. Liu, E. Zhang, Q. Liu, X. Yu, B. Lu, MoSe $2 /$ N-doped carbon as anodes for potassium-ion batteries. Adv. Energy Mater. 8, 1801477 (2018)

19. B. Kirubasankar, S. Vijayan, S. Angaiah, Sonochemical synthesis of a 2D-2D MoSe 2 /graphene nanohybrid electrode material for asymmetric supercapacitors. Sustainable energy fuels $3,467-477$ (2019)

20. S. Zhang, T. Nguyen, W. Zhang, Y. Park, W. Yang, Correlation between lateral size and gas sensing performance of $\mathrm{MoSe}_{2}$ nanosheets. Appl. Phys. Lett. 111, 161603 (2017)

21. X. Chen, X. Chen, Y. Han, C. Su, M. Zeng, N. Hu, Y. Su, Z. Zhou, H. Wei, Z. Yang, Two-dimensional $\mathrm{MoSe}_{2}$ nanosheets via liquid-phase exfoliation for high-performance room temperature $\mathrm{NO}_{2}$ gas sensors. Nanotechnology 30, 445503 (2019)

22. D. Zhang, Q. Li, P. Li, M. Pang, Y. Luo, Fabrication of Pd-decorated $\mathrm{MoSe}_{2}$ nanoflowers and density functional theory simulation toward ammonia sensing. IEEE Electron Device Lett. 40, 616-619 (2019)

23. B. Yao, L. Huang, J. Zhang, X. Gao, J. Wu, Y. Cheng, X. Xiao, B. Wang, Y. Li, J. Zhou, Flexible transparent molybdenum trioxide nanopaper for energy storage. Adv. Mater. 28, 6353-6358 (2016)

24. Z. Li, W. Wang, Z. Zhao, X. Liu, P. Song, One-step hydrothermal preparation of Ce-doped $\mathrm{MoO}_{3}$ nanobelts with enhanced gas sensing properties. RSC Adv. 7, 28366 (2017)

25. J. Huang, B. Jin, H. Liu, X. Li, Q. Zhang, S. Chu, R. Peng, S. Chu, Controllable synthesis of flower-like $\mathrm{MoSe}_{2}$ microspheres for highly efficient visible-light photocatalytic degradation of nitro-aromatic explosives. J. Mater. Chem. A 6, 11424 (2018)

26. H. Li, L. Huang, X. Wang, C. Lee, J. Yoon, J. Zhou, X. Guo, J. Lee, Molybdenum trioxide nanopaper as a dual gas sensor for detecting trimethylamine and hydrogen sulfide. RSC Adv. 7, 3680 (2017) 
27. D. Zeng, P. Wu, W. Ong, B. Tang, M. Wu, H. Zheng, Y. Chen, D. Peng, Construction of network-like and flower-like $2 \mathrm{H}-\mathrm{MoSe}_{2}$ nanostructures coupled with porous $\mathrm{g}-\mathrm{C}_{3} \mathrm{~N}_{4}$ for noble-metal-free photocatalytic $\mathrm{H}_{2}$ evolution under visible light. Appl. Catal. B 233, 26-34 (2018)

28. J. Zhang, W. Kang, M. Jiang, Y. You, Y. Cao, T. Ng, D. Yu, C. Lee, J. Xu, Conversion of $1 \mathrm{~T}-\mathrm{MoSe}_{2}$ to $2 \mathrm{H}-$ $\mathrm{MoS}_{2 \mathrm{x}} \mathrm{Se}_{2-2 \mathrm{x}}$ mesoporous nanospheres for superior sodium storage performance. Nanoscale 9 , 1484-1490 (2017)

29. X. Wang, Y. Zhang, Z. Chen, Effect of $\mathrm{MoO}_{3}$ constituents on the growth of $\mathrm{MoS}_{2}$ nanosheets by chemical vapor deposition. Mater. Res. Express 3, 065014 (2016)

30. D. Wang, K. Gu, Q. Zhao, C. Zhai, T. Yang, Q. Lu, J. Zhang, M. Zhang, Synthesis and trimethylamine sensing properties of spherical $\mathrm{V}_{2} \mathrm{O}_{5}$ hierarchical structures. New J. Chem 42, 14188 (2018)

31. F. Zhang, X. Dong, X. Cheng, Y. Xu, X. Zhang, L. Huo, Enhanced gas-sensing properties for trimethylamine at low temperature based on $\mathrm{MoO}_{3} / \mathrm{Bi}_{2} \mathrm{Mo}_{3} \mathrm{O}_{12}$ hollow microspheres. ACS Appl. Mater. Interfaces 11, 11755-11762 (2019)

32. V. Mounasamy, G. Mani, D. Ponnusamy, K. Tsuchiya, A. Prasad, S. Madanagurusamy, Sub-ppm level detection of trimethylamine using $\mathrm{V}_{2} \mathrm{O}_{3}-\mathrm{Cu}_{2} \mathrm{O}$ mixed oxide thin films. Ceram. Int. 45, 19528-19533 (2019)

33. D. Meng, J. Si, M. Wang, G. Wang, Y. Shen, X. San, F. Meng, One-step synthesis and the enhanced trimethylamine sensing properties of $\mathrm{Co}_{3} \mathrm{O}_{4} / \mathrm{SnO}_{2}$ flower-like structures. Vacuum 171, 108994 (2020)

34. Z. Ma, P. Song, Z. Yang, Q. Wang, Trimethylamine detection of 3D rGO/mesoporous $\ln _{2} \mathrm{O}_{3}$ nanocomposites at room temperature. Appl. Surf. Sci. 465, 625-634 (2019)

35. B. Balachandar, T. Logu, R. Ramprasath, K. Sankarasubramanian, P. Soundarrajan, M. Sridharan, K. Ramamurthi, K. Sethuraman, Spray pyrolysis deposited CdO: Al films for trimethylamine sensing application. Mater. Sci. Semicond. Process. 105, 104753 (2020)

36. Q. Qi, Y. Zou, M. Fan, Y. Liu, S. Gao, P. Wang, Y. He, D. Wang, G. Li, Trimethylamine sensors with enhanced anti-humidity ability fabricated from $\mathrm{La}_{0.7} \mathrm{Sr}_{0.3} \mathrm{FeO}_{3}$ coated $\mathrm{In}_{2} \mathrm{O}_{3}-\mathrm{SnO}_{2}$ composite nanofibers. Sens. Actuators, B 203, 111-117 (2014)

37. Y. Luo, S. Hu, H. Wang, Y. Chen, J. Dong, Z. Jiang, X. Xiong, W. Zhu, W. Qiu, H. Lu, H. Guan, Y. Zhong, J. Yu, J. Zhang, Z. Chen, Sensitivity-enhanced surface plasmon sensor modified with $\mathrm{MoSe}_{2}$ overlayer. Opt. Express 26, 34250-34258 (2016)

38. N. Vishnu, S. Badhulika, Single step synthesis of $\mathrm{MoSe}_{2}-\mathrm{MoO}_{3}$ heterostructure for highly sensitive amperometric detection of nitrite in water samples of industrial areas. Electroanalysis 31, 24102416 (2019)

39. Z. Yang, D. Zhang, D. Wang, Carbon monoxide gas sensing properties of metal-organic frameworksderived tin dioxide nanoparticles/molybdenum diselenide nanoflowers. Sens. Actuators, B 304, 127369 (2020)

40. Z. Li, P. Song, Z. Yang, Q. Wang, In situ formation of one-dimensional $\mathrm{CoMoO}_{4} / \mathrm{MoO}_{3}$ heterojunction as an effective trimethylamine gas sensor. Ceram. Int. 44, 3364-3370 (2018) 
Figures

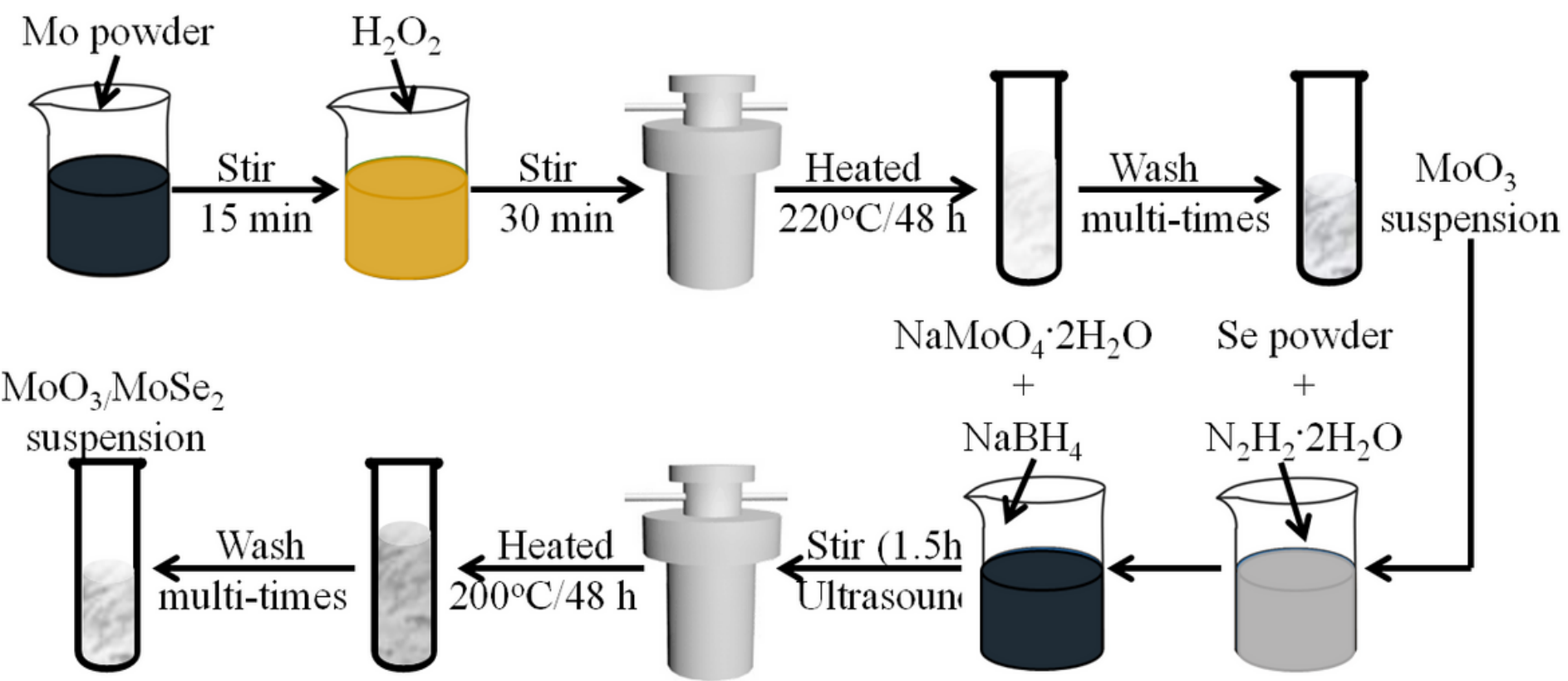

Figure 1

Manufacturing process of MoO3/MoSe2 nanocomposite. 


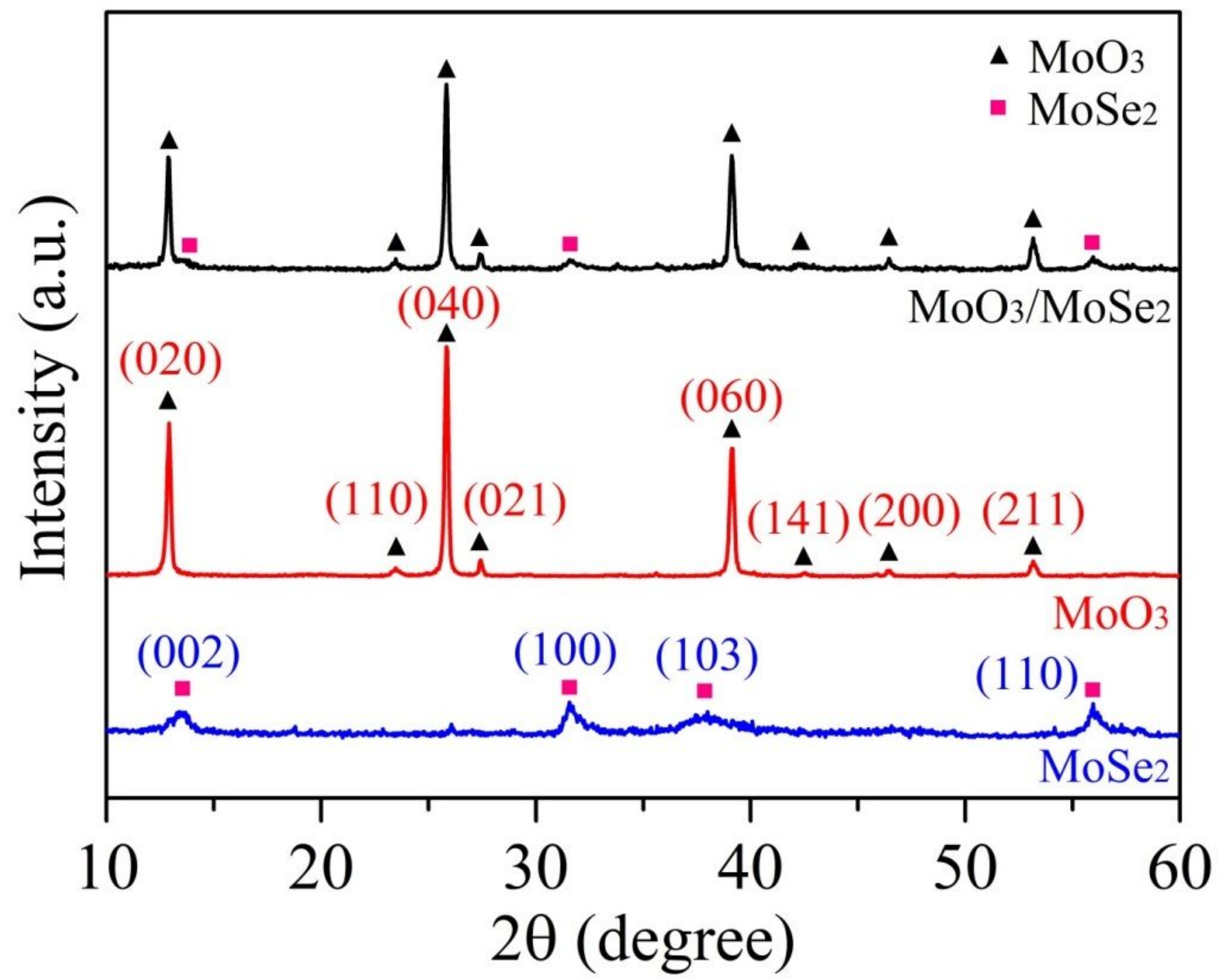

Figure 2

XRD patterns of MoSe2, $\mathrm{MoO} 3$ and $\mathrm{MoO} 3 / \mathrm{MoSe} 2$ nanocomposite. 

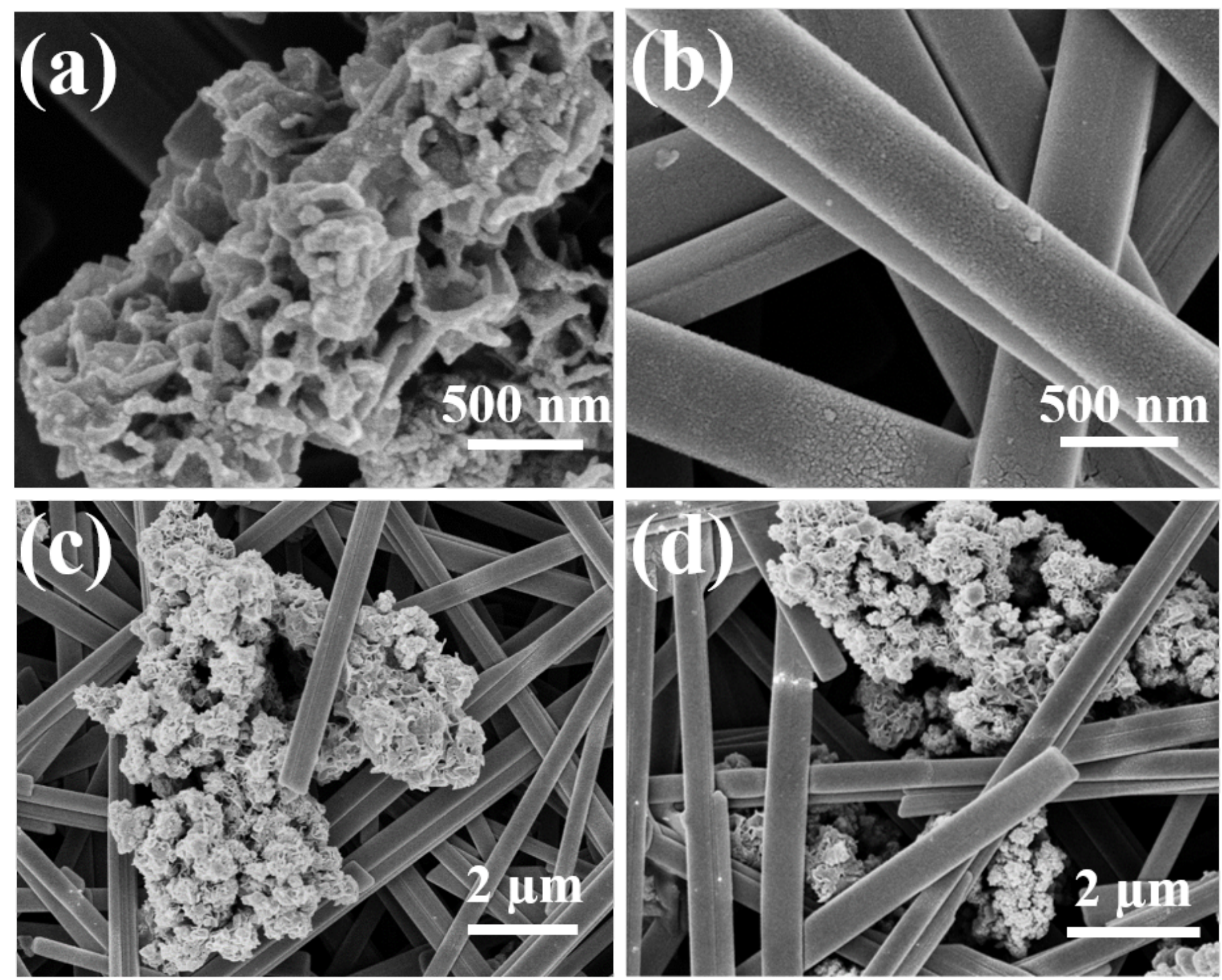

Figure 3

SEM characterization: (a) MoSe2, (b) MoO3, and (c-d) MoO3/MoSe2 nanocomposite. 

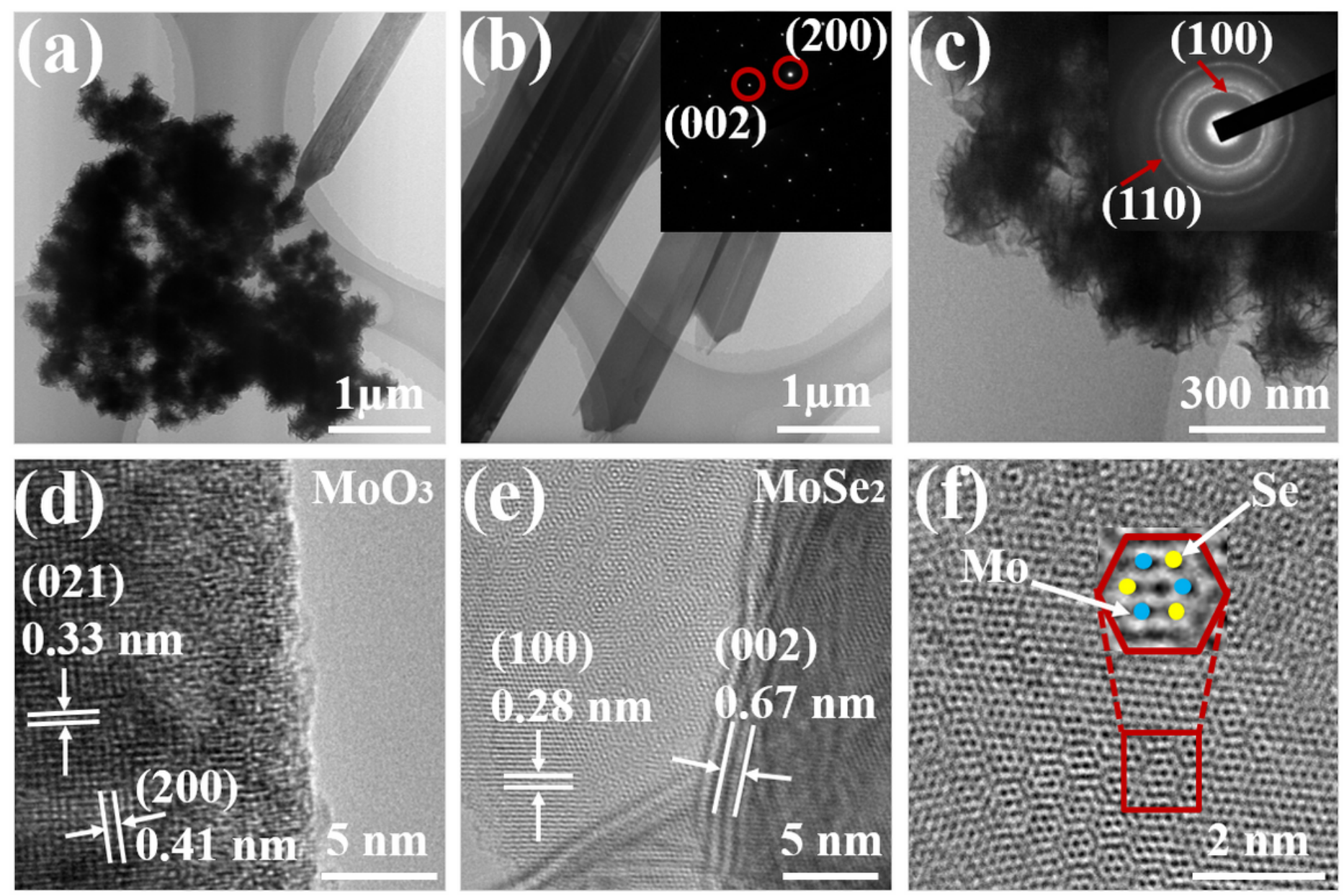

\section{Figure 4}

TEM characterization: (a) MoO3/MoSe2, (b-c) MoO3 and MoSe2. The inset is the electron diffraction pattern (SAED). (d-e) High-resolution TEM images of MoO3/MoSe2 nanocomposite. (f) Schematic diagram of the surface atomic distribution of MoSe2. 

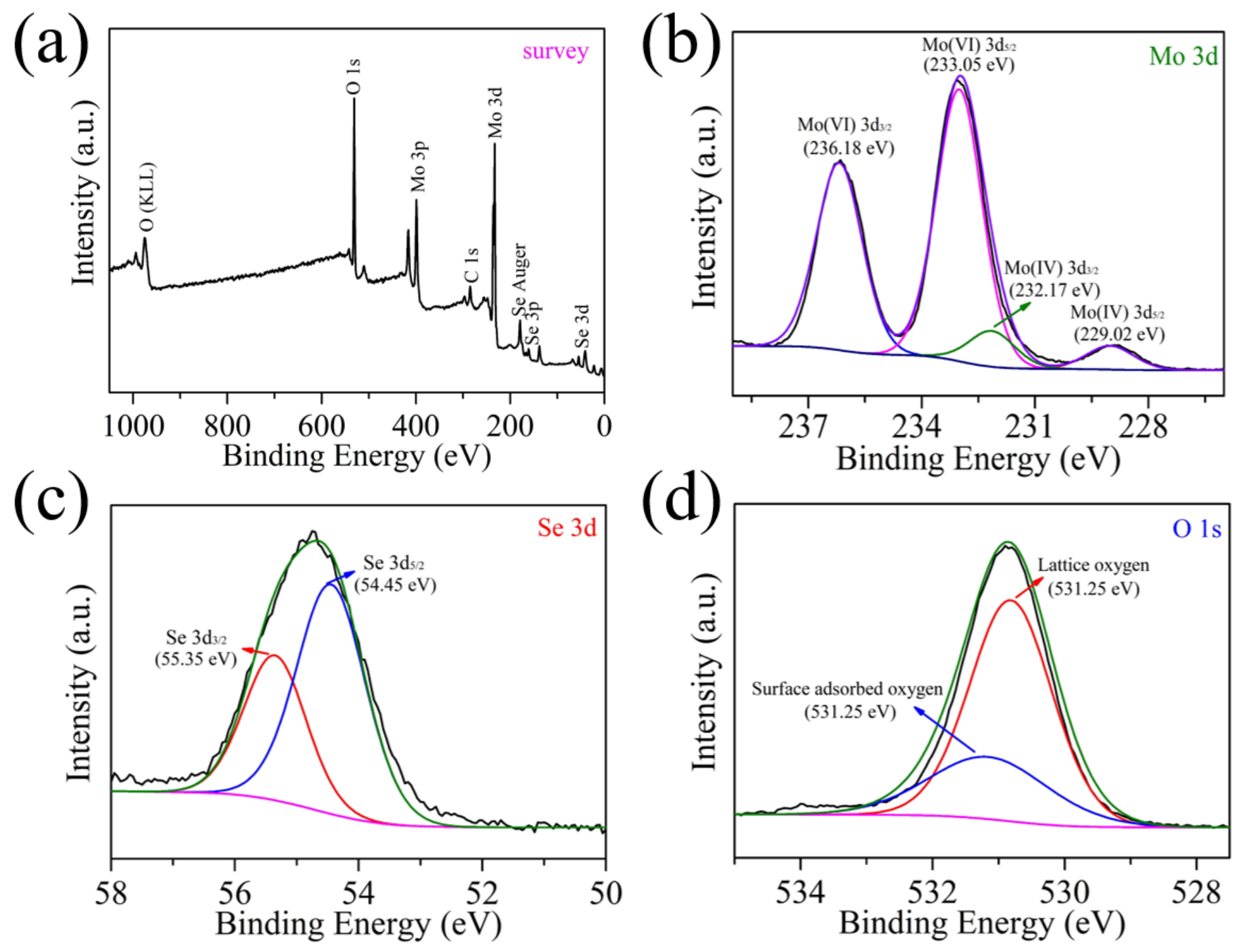

Figure 5

XPS spectra of MoO3/MoSe2 nanocomposite: (a) survey, (b) Mo 3d, (c) Se 3d, and (d) 0 1s. 


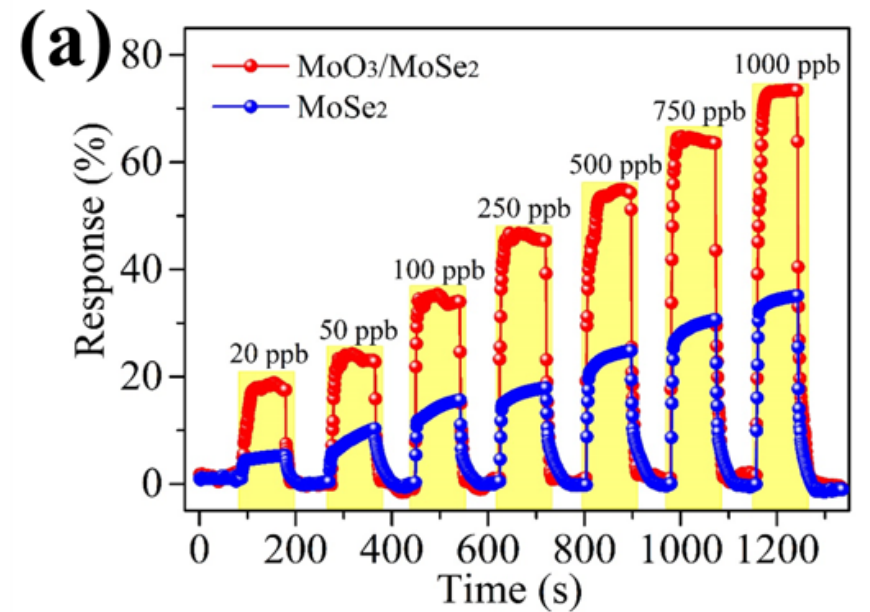

(c)

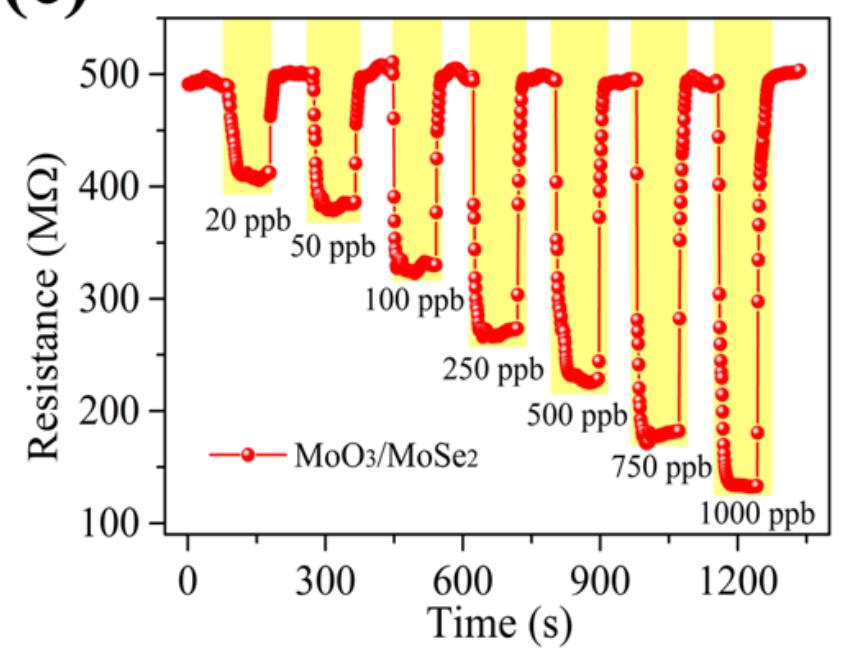

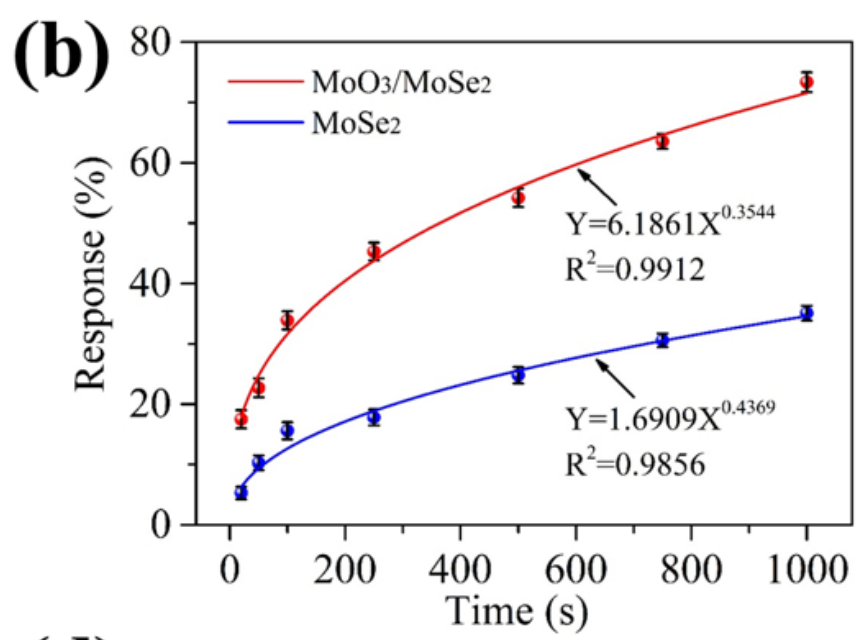

(d)

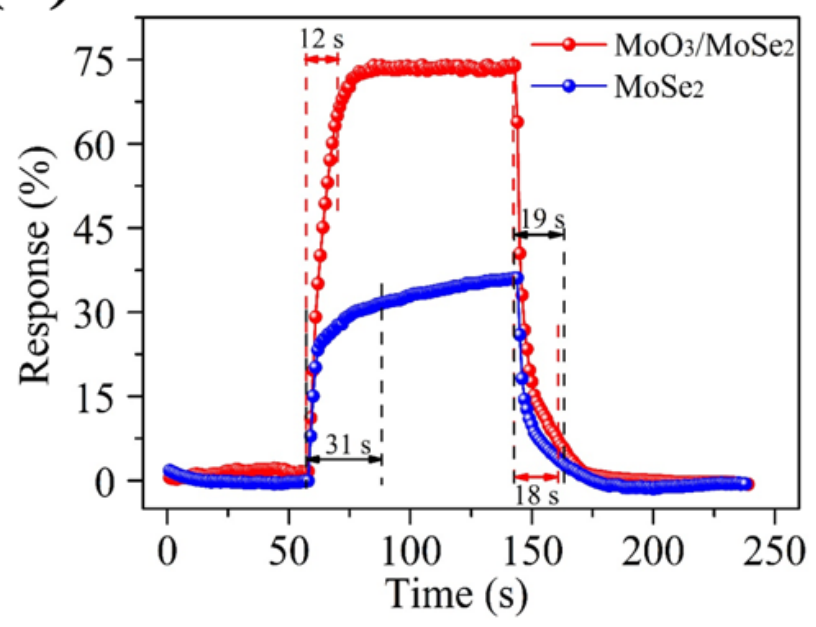

Figure 6

MoSe2 and MoO3/MoSe2 nanocomposite sensors at room temperature. (a) Plot of sensor response as a function of time. (b) Plot of sensor response as a function of gas concentration. (c) Dynamic resistance change of MoO3/MoSe2 nanocomposite sensor. (d) Response/recovery characteristics of the two sensors to $1000 \mathrm{ppb}$ TMA. 

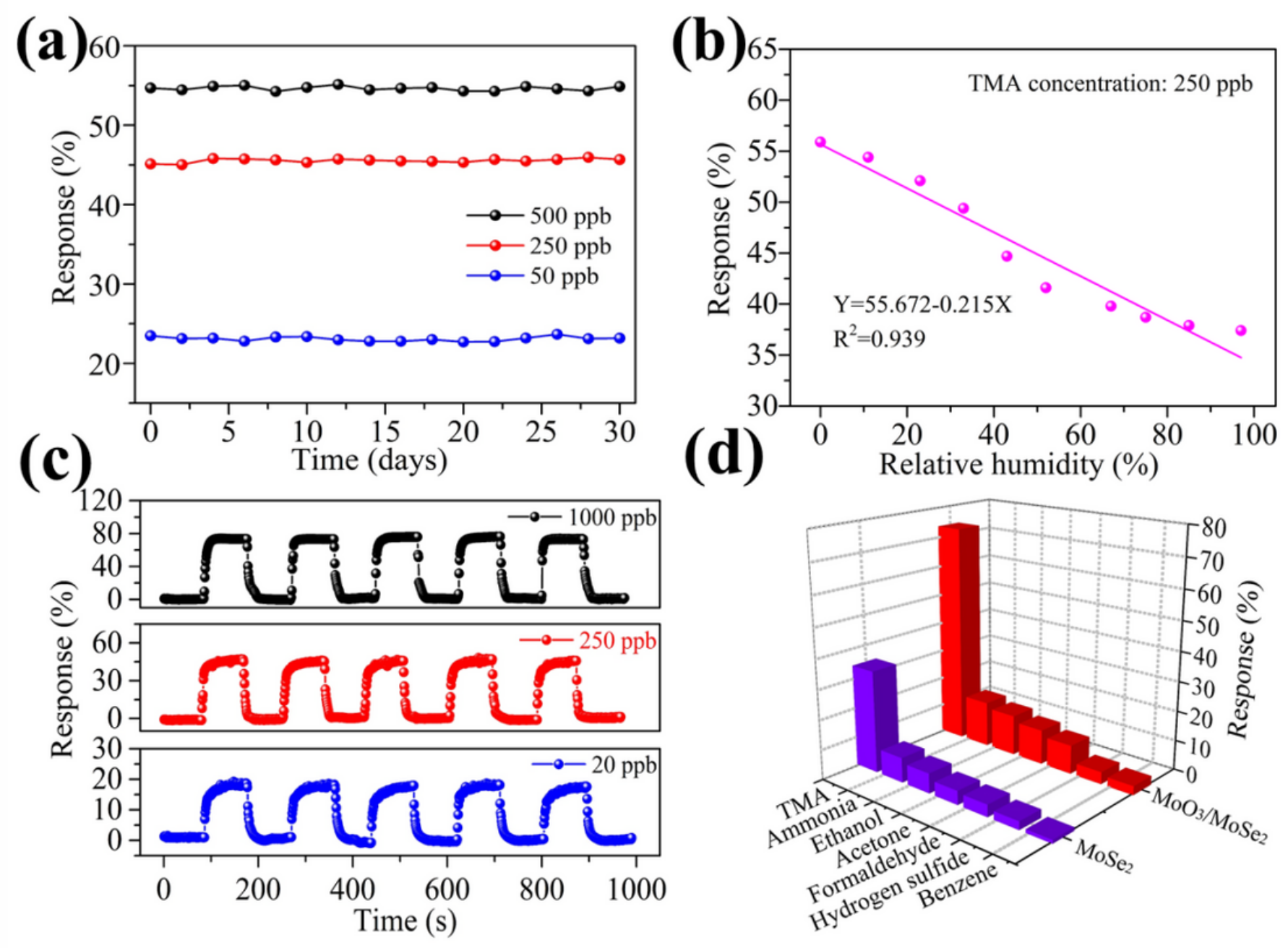

Figure 7

MoSe2 and MoO3/MoSe2 sensors at room temperature. (a) Long-term stability test of MoO3/MoSe2 sensor. (b) Fit curve of relative humidity and MoO3/MoSe2 sensor response in $250 \mathrm{ppb}$ TMA. (c) Repeatability test results of MoO3/MoSe2 sensor. (d) Selectivity test results of MoSe2 sensor and Mo03/MoSe2 nanocomposite sensor in 1000 ppb concentration of different detected gases.

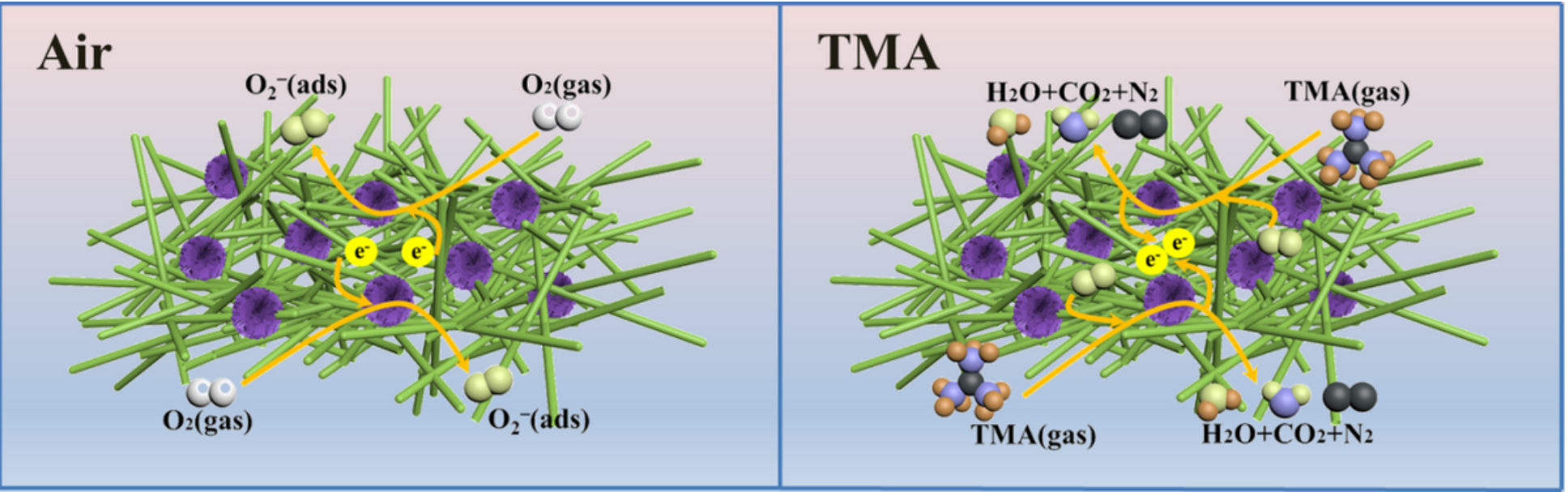

Figure 8 
Schematic diagram of TMA sensing mechanism of MoO3/MoSe2 sensor.
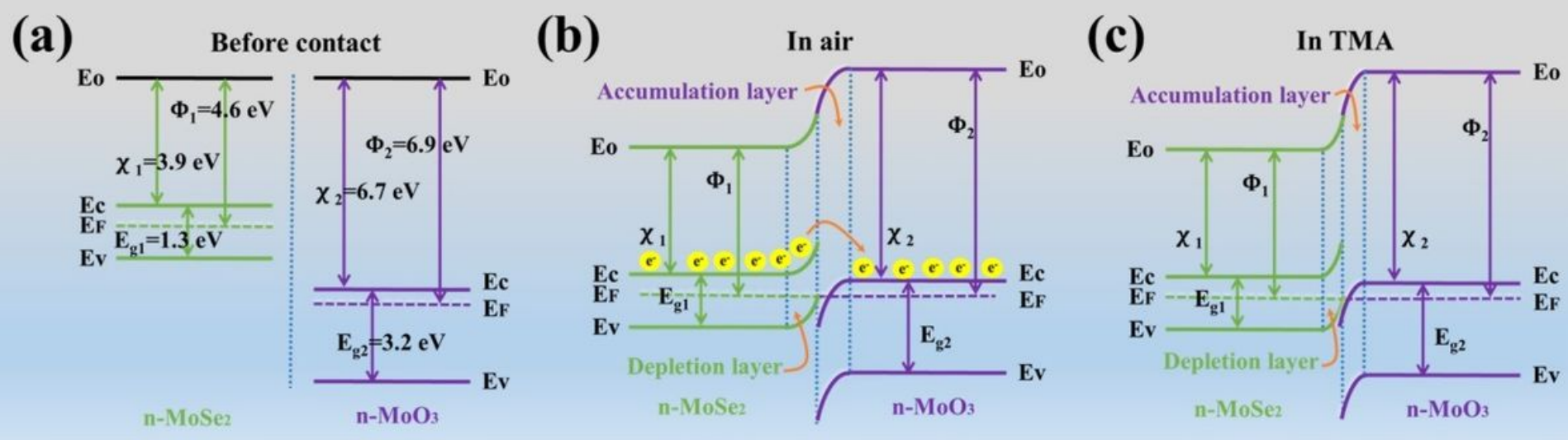

\section{Figure 9}

Energy band diagrams of MoO3/MoSe2 nanocomposite: (a) before contact, (b) in air, and (c) TMA. 